\title{
Analysis of the Development of the Nasal Septum and Measurement of the Harvestable Septal Cartilage in Koreans Using Three-Dimensional Facial Bone Computed Tomography Scanning
}

\author{
Jae Hee Kim, Dong Ju Jung, Hyo Seong Kim, Chang Hyun Kim, Tae Yeon Kim \\ Department of Plastic and Reconstructive Surgery, Bundang Jesaeng General Hospital, Seongnam, Korea
}

Background The septal cartilage is the most useful donor site for autologous cartilage graft material in rhinoplasty. For successful nasal surgery, it is necessary to understand the developmental process of the nasal septum and to predict the amount of harvestable septal cartilage before surgery.

Methods One hundred twenty-three Korean patients who underwent three-dimensional (3D) facial bone computed tomography (CT) were selected for evaluation of the midsagittal view of the nasal septum. Multiple parameters such as the area of each component of the nasal septum and the amount of harvestable septal cartilage were measured using Digimizer software.

Results The area of the total nasal septum showed rapid growth until the teenage years, but thereafter no significant change throughout the lifetime. However, the development of the septal cartilage showed a gradual decline due to ossification changes with aging after puberty in spite of a lack of change in the total septal area. The area of harvestable septal cartilage in young adults was $549.84 \pm 151.26 \mathrm{~mm}^{2}$ and decreased thereafter with age.

Conclusions A 3D facial bone CT scan can provide valuable information on the septal cartilage graft before rhinoplasty. Considering the developmental process of the septal cartilage identified in this study, septal surgery should not be performed until puberty due to the risk of nasal growth impairment. Furthermore, in elderly patients who show a decreased cartilage area due to ossification changes, septal cartilage harvesting should be performed carefully due to the risk of saddle nose deformity.

Keywords Nasal septum / Nasal cartilage / Multidetector computed tomography
Correspondence: Tae Yeon Kim Department of Plastic and

Reconstructive Surgery,

Bundang Jesaeng General Hospital,

20 Seohyun-ro 180beon-gil,

Bundang-gu, Seongnam 463-774,

Korea

Tel: +82-31-779-0392

Fax: +82-31-779-0164

E-mail: kty@dmc.or.kr

No potential conflict of interest relevant to this article was reported.

Received: 30 May 2013 • Revised: 13 Aug 2013 - Accepted: 14 Aug 2013

pISSN: 2234-6163 • elSSN: 2234-6171 • http://dx.doi.org/10.5999/aps.2014.41.2.163・Arch Plast Surg 2014;41:163-170

\section{INTRODUCTION}

The nasal septum consists of septal cartilage, the perpendicular plate of the ethmoid (PPE) bone, and the vomer. The septal cartilage is the most useful donor site for an autogenous cartilage graft.
The advantages of septal cartilage for augmentation rhinoplasty are the ease of harvest under the same surgical field, high biocompatibility, and a low risk of infection as an autogenous material [14]. In the nasal septal cartilage harvesting procedure, care should be taken not to damage the nasal framework balance by preserv- 
ing the keystone area. The purpose of this study was not only to evaluate the developmental process of the nasal septum but also to enable the prediction of the amount of harvestable septal cartilage before surgery to achieve successful rhinoplasty.

Many studies have quantified the amount of nasal septum available for grafting [5-9]. However, these studies have had several limitations. In a study of human cadavers $[5,6]$, the samples were few in number, and almost all were over 60 years old. In a study of cosmetic surgery [7], there was no mention of age. In a radiological study, paranasal sinus (PNS) computed tomography (CT) [8] did not provide a sagittal view; therefore, the sagittal view required reconstruction through additional procedures. Magnetic resonance imaging (MRI) [9] demonstrates precise views of soft tissues and rountinely provides sagittal images, but has the drawback of high cost and is rarely used in plastic surgery. On the other hand, a 3-dimensional (3D) facial bone CT scan, which is often performed in facial plastic surgery, provides sagittal images routinely and can demonstrate excellent views of the nasal septum by distinguishing the border of the bony structure at minimal cost.

This is the first study using 3D facial bone CT scaning to evaluate the amount of nasal septum available for grafting. We performed an analysis of the development of the total nasal septum and the septal cartilage, comparing gender and age groups using the midsagittal images of 152 patients who had no previous history of a septal procedure or nasal trauma. We also measured the area of harvestable septal cartilage including the dorsal and caudal length, assuming the preservation of a 10-mm-wide safety Lstrut.

\section{METHODS}

Among 572 patients who underwent 3D facial bone CT scan for diagnosis from August 2006 to February 2013, we retrospectively studied 123 patients who had normal septal anatomy without nasal or zygomaticomaxillary bone fracture. Those with severe septal deviations or a history of previous septoplasty or

\section{Table 1. Age and gender distribution of the patients}

\begin{tabular}{|lccr|}
\hline Age group (yr) & Male & Female & Total \\
\hline $0-9$ & 4 & 0 & 4 \\
$10-19$ & 17 & 3 & 20 \\
$20-29$ & 13 & 3 & 16 \\
$30-39$ & 17 & 3 & 20 \\
$40-49$ & 21 & 7 & 28 \\
$50-59$ & 4 & 4 & 8 \\
$60-69$ & 6 & 4 & 10 \\
$70-99$ & 8 & 9 & 17 \\
Total & 90 & 33 & 123 \\
\hline
\end{tabular}

rhinoplasty were excluded.

\section{Age and gender distribution}

Our clinical study included 90 male and 33 female patients. Their age ranged from 4 to 99 years, and the mean age was 41.39 years (Table 1).

\section{CT protocol and the selection of the best midsagittal image for the total nasal septum}

3D Facial 64 multi-detector CT scan (Siemens, Somatom Sensation 64, Forchheim, Germany) images were acquired at 120 $\mathrm{kV}$ and $150 \mathrm{mAs}$ with a 1 minute scanning time. The serial images included $2 \mathrm{~mm}$ slices of axial, coronal, and sagittal images. All of the images were examined using the PiViewSTAR program (Infinitt, Seoul, Korea). The midsagittal image was defined as the view through the midline of the cerebrum by simultaneously crosslinking with the coronal and axial images. Then, from the three sagittal images including both adjacent side images, we selected the one that showed the best image of the total nasal septum (Fig. 1).

\section{Measurement of the area of each component of the total nasal septum}

We defined the total nasal septum as a combination of three components: the septal cartilage, PPE bone, and vomer. The sphenoidal process of the septal cartilage, also called the septal tail, which was a small strip of cartilage between the PPE and vomer, was included in the area of the septal cartilage.

We used Digimizer ver. 3.1.2.0 software (MedCalc Software, Mariakerke, Belgium) to measure the area of each component of the total nasal septum according to the following procedure: First, the 13 cardinal points were digitally placed to plot the anatomic boundaries of each component of the total septum.

Fig. 1. A mid-sagittal image generated by simultaneously crosslinking images

(A-D) Three-dimensional facial bone computed tomography scan showing the best mid-sagittal image of the total nasal septum by crosslinking the coronal and axial images.
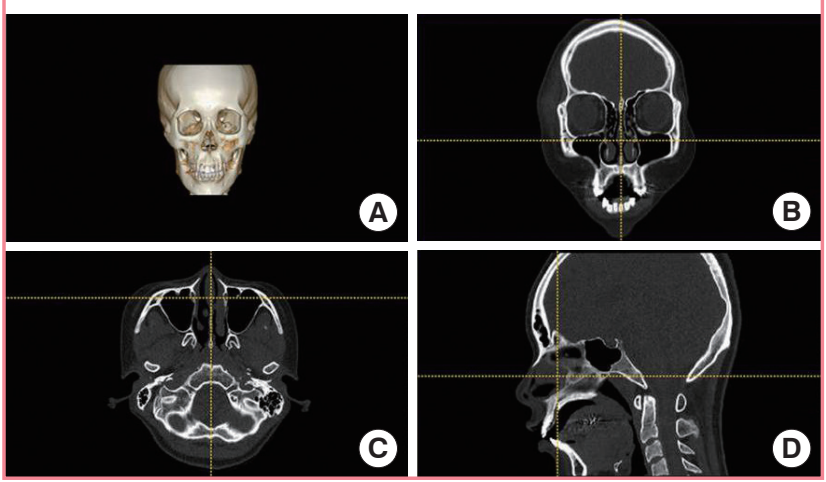


\section{Fig. 2. Measurement of the nasal septum}

Measurement of the area of each component using Digimizer software. $A$, anteriormost end of the septal cartilage; $B$, anterior end of the inferior edge of the nasal bone; $C_{1}$ crossing point of the inferior edge of the nasal bone and suture line between the septal cartilage and PPE; D, posterior end of the inferior edge of the nasal bone; $E_{\text {, }}$ posterior end of the inferior edge of the frontal sinus; $F$, superiormost end of the anterior wall of the sphenoid sinus; $G$, inferior end of the anterior wall of the sphenoid sinus; $H$, posterior end of the inferior wall of the sphenoid sinus; $I$, posterior end of the palate bone on the nasal floor; J, anterior nasal spine; $K$, inferiormost points of the caudal margin of the cartilaginous septum; $L$, breaking point of the suture line between the septal cartilage and PPE; $M$, the junctional point of the septal cartilage, PPE, and vomer; PPE, perpendicular plate of the ethmoid; SP, sphenoid process of the septal cartilage.

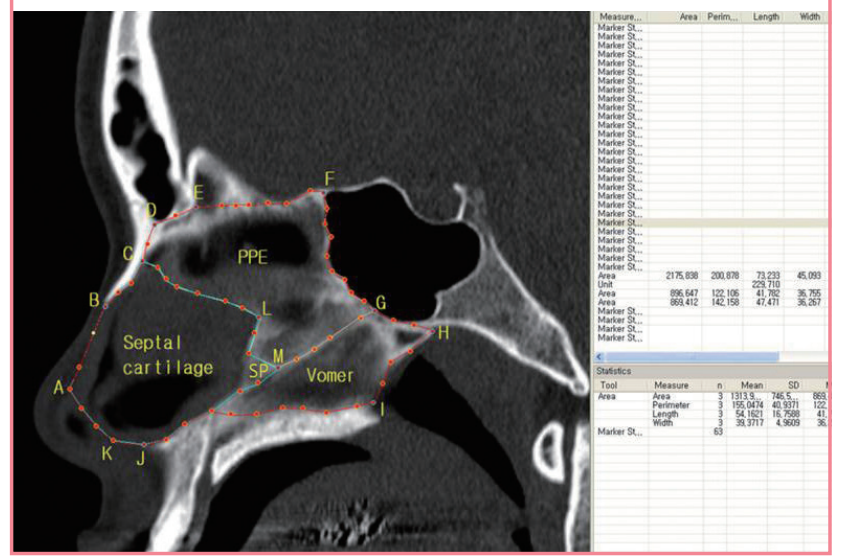

They were placed on the selected image in which the total nasal septum could be best visualized. The 13 cardinal points were labeled from A to M. Second, about 40 points were added along the irregularly curved border of each component of the total nasal septum for calculation of the precise area. Finally, adjacent points were connected by straight lines, and the area of each component was calculated using Digimizer software (Fig. 2).

\section{Measurement of the area of the harvestable septal cartilage}

Assuming the preservation of a 10 -mm-wide safety L-strut, we defined points as A (anteriormost end of the septal cartilage), $\mathrm{B}$ (anterior end of the inferior edge of the nasal bone), and $\mathrm{K}$ (inferiormost points of the caudal margin of the cartilaginous septum) to calculate the area of the harvestable septal cartilage, that is, the entire septum minus the L-strut. Two lines were drawn in the septal cartilage, an A-B line and A-K line. Then, two imaginary lines parallel to the A-B and A-K lines $10 \mathrm{~mm}$ apart from each other $(a, b)$ were drawn in the septal cartilage using the Digimizer software. The dorsal and caudal length (DL and CL) of the harvestable septal cartilage and the area of harvestable septal cartilage assuming the preservation of a $10-\mathrm{mm}$ wide safety L-strut were defined, and they were measured using Digimizer software (Fig. 3).

\section{Fig. 3. Measurement of the harvestable septal cartilage}

Measurement of the linear dimensions and areas of the harvestable septal cartilage assuming preservation of a $10-\mathrm{mm}$-wide safety L-strut. $A$, anteriormost end of the septal cartilage; $B$, anterior end of the inferior edge of the nasal bone; $K$, inferiormost points of the caudal margin of the cartilaginous septum; LS, imaginary 10-mmwide safety L-strut; HSC, harvestable septal cartilage; $a$, dorsal width of $L$-strut $=10 \mathrm{~mm} ; b$, caudal width of L-strut $=10 \mathrm{~mm}$ (yellow arrow line); $\mathrm{DL}$, dorsal length of harvestable septal cartilage; $C L$, caudal length of harvestable septal cartilage (red arrow line).

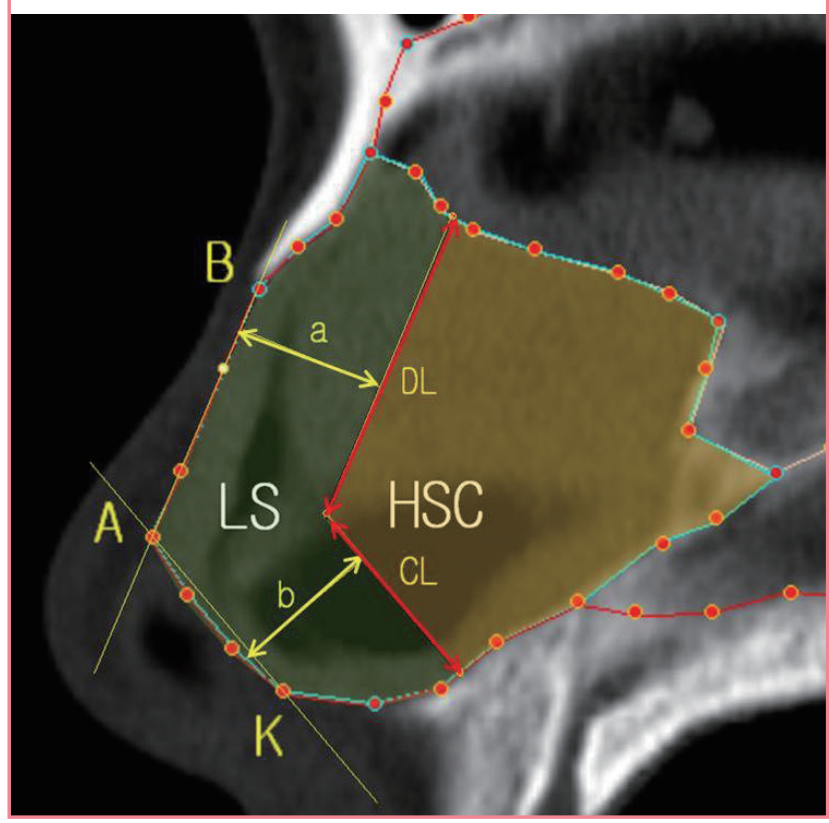

\section{Statistical methods}

Statistical analysis was performed using PASW Statistics ver. 18.0 (IBM Inc., Armonk, NY, USA). Bivariate correlations were used to determine the relationships among the area and the ratio of each component of the nasal septum including the harvestable septal cartilage according to the age group. An independent $t$-test was conducted to determine the difference between the males and females. Differences were considered to be statistically significant when the P-value was less than 0.05 .

\section{RESULTS}

\section{The area of each component of the nasal septum}

The areas of the septal cartilage and total septum were $872.47 \pm$ $220.37 \mathrm{~mm}^{2}$ and $2,561.89 \pm 366.57 \mathrm{~mm}^{2}$, respectively. The ratio of the septal cartilage to the total nasal septum was 0.34 (Table 2).

\section{The area and the ratio of each component of the nasal septum according to gender}

The areas of the total nasal septum and septal cartilage were significantly larger in the males than the females $(\mathrm{P}<0.05)$ (Table 3 ). The ratio of septal cartilage was also significantly higher in 
Table 2. The area of each nasal septal component

\begin{tabular}{|c|c|c|c|c|}
\hline Area $\left(\mathrm{mm}^{2}\right)$ & SC & PPE & Vomer & TS \\
\hline Mean \pm SD (ratio $\left.{ }^{a}\right)$ & $872.47 \pm 220.37(0.34)$ & $1,039.81 \pm 215.10(0.41)$ & $649.58 \pm 171.79(0.25)$ & $2,561.89 \pm 366.57(1)$ \\
\hline Min-max (median) & $443.79-1,410.70$ (850.79) & $430.95-1,436.80(1,064.10)$ & $303.27-1,130.70$ (662.38) & $1,547.50-3,511.90(2,597.30)$ \\
\hline
\end{tabular}

Table 3 . The area of the nasal septum by gender

\begin{tabular}{|c|c|c|c|c|}
\hline Gender & $\mathrm{SC}\left(\mathrm{mm}^{2}\right)$ & PPE $\left(\mathrm{mm}^{2}\right)$ & Vomer $\left(\mathrm{mm}^{2}\right)$ & $\mathrm{TS}\left(\mathrm{mm}^{2}\right)$ \\
\hline \multicolumn{5}{|l|}{ Male } \\
\hline Mean \pm SD & $932.84 \pm 197.22$ & $1,053.40 \pm 223.11$ & $672.07 \pm 175.22$ & $2,660.30 \pm 325.57$ \\
\hline Min-max (median) & $553.09-1,410.70$ (915.25) & $430.95-1,436.80(1,097.95)$ & $325.68-1,130.70$ (686.52) & $1,590.10-3,511.90(2,668.10)$ \\
\hline \multicolumn{5}{|l|}{ Female } \\
\hline Mean \pm SD & $707.83 \pm 196.87$ & $1,002.76 \pm 189.79$ & $588.23 \pm 147.71$ & $2,293.48 \pm 340.53$ \\
\hline Min-max (median) & $443.79-1,095.50$ (693.31) & $635.87-1,436.60(1,010.80)$ & $303.27-902.83$ (608.88) & $1,547.50-3,067.90(2,264.70)$ \\
\hline P-value & $<0.001$ & 0.249 & 0.016 & $<0.001$ \\
\hline
\end{tabular}

\section{Fig. 4. The ratio of each nasal septum component by gender}

The ratio of each component of the nasal septum according to gender. SC, septal cartilage; PPE, perpendicular plate of the ethmoid. Values are presented as the ratio of each component to the total septum. ${ }^{\text {al }} P$ $<0.001 ;{ }^{\text {b) }} \mathrm{P}=0.005$; $^{\mathrm{c}} \mathrm{P}=0.763$.

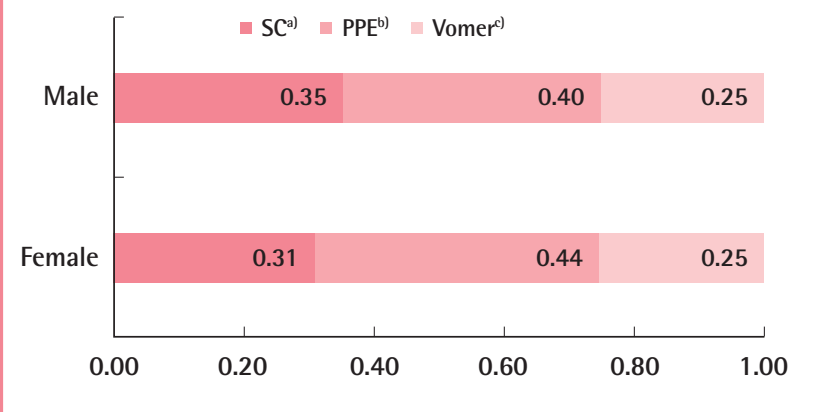

the males than females $(\mathrm{P}<0.05)$ (Fig. 4).

\section{The area and the ratio of each component of the nasal} septum according to age

The areas of the total septum and the septal cartilage were $2,567.62 \pm 287.46 \mathrm{~mm}^{2}$ and $1,055.03 \pm 192.36 \mathrm{~mm}^{2}$, respectively, in the teenage group. Thereafter, the total septum showed no significant change after the twenties from $2,580.52 \pm 251.76 \mathrm{~mm}^{2}$ in the twenties age group to $2,325.17 \pm 448.71 \mathrm{~mm}^{2}$ in the group over 70 years of age $(\mathrm{P}>0.05)$. However, the septal cartilage was significantly reduced in area with age, from $1,055.03 \pm 192.36$ $\mathrm{mm}^{2}$ in the teenage group to $696.92 \pm 202.07 \mathrm{~mm}^{2}$ in the group over $70(\mathrm{P}<0.05)($ Table 4$)$. The ratio of the septal cartilage to the total septum also decreased with age from 0.41 in the teenage group to 0.30 in the over 70 group $(\mathrm{P}<0.05)$ (Fig. 5$)$.

\section{The area and linear dimensions of the harvestable septal cartilage}

The average area of the harvestable septal cartilage, assuming preservation of a 10-mm-wide safety L-strut, was $497.32 \pm 181.65$ $\mathrm{mm}^{2}$ (Table 5). The ratio of the harvestable septal cartilage to the total septum was 0.19 . The dorsal and caudal length of the harvestable septal cartilage were $19.58 \pm 5.09 \mathrm{~mm}$ and $15.15 \pm 3.13$ $\mathrm{mm}$ (Table 6). The area of the harvestable septal cartilage significantly decreased with age $(\mathrm{P}<0.05)($ Table 5$)$. The area of harvestable septal cartilage was significantly larger in the males than females $(\mathrm{P}<0.05)$ (Table 6).

\section{DISCUSSION}

The septal cartilage is the primary choice for autogenous grafts in rhinoplasty. It can be used in various ways, including tip grafts, dorsal onlay grafts, columellar strut grafts, and nasal spreader grafts [1-4]. However, the major limitation is that the amount of harvestable cartilage is insufficient and unpredictable, especially for the multiple graft procedures of rhinoplasty.

A 3D facial bone CT scan is very commonly taken for the diagnosis of facial trauma in all age groups. We used a midsagittal view of the 3D facial bone CT scan to quantify the area of each part of the nasal septum by age and gender. Unlike previous studies with cadavers, living subjects undergoing cosmetic 
Table 4 . The area of the nasal septum by age

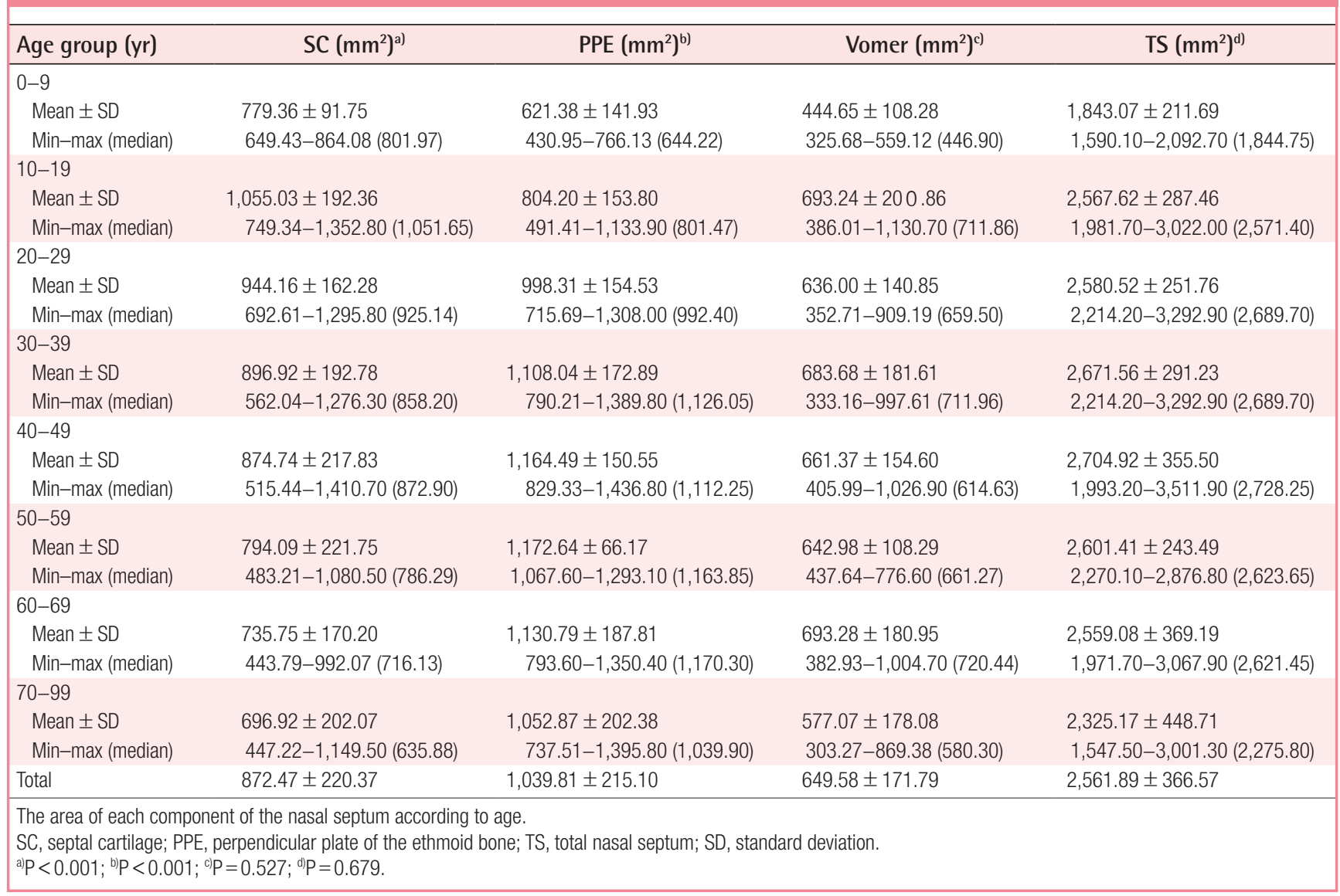

\section{Fig. 5. The ratio of each nasal septum component by age}

The ratio of each component of the nasal septum according to age. SC, septal cartilage; PPE, perpendicular plate of the ethmoid. Values are presented as the ratio of each component to the total septum. ${ }^{\text {al }} \mathrm{P}$ $<0.001 ;{ }^{\text {b) }} \mathrm{P}<0.001 ;{ }^{\mathrm{c}} \mathrm{P}=0.574$.

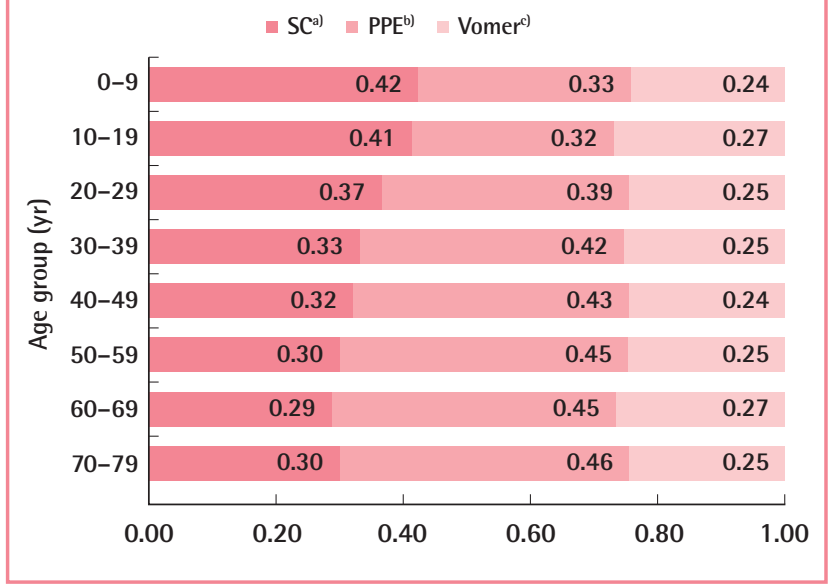

procedures, and living subjects using PNS CT and MRI [5-9], using 3D facial bone CT in this study enabled the collection of data from many subjects across age groups and produced clear anatomical images of the nasal septum at low cost. Using the data we collected, we were able to analyze the nasal septal development and predict the harvestable amount of septal cartilage by age and gender.

Compared with other studies, the mean area of the total nasal septum in this study $\left(2,561.89 \mathrm{~mm}^{2}\right)$ was similar to those found in a cadaver study $\left(2,578.7 \mathrm{~mm}^{2}\right)[5]$, in a PNS study $(2,731.66$ $\left.\mathrm{mm}^{2}\right)$ [8], and in a MRI study $\left(2,127 \mathrm{~mm}^{2}\right)$ [9]. The mean area of the septal cartilage $\left(872.47 \mathrm{~mm}^{2}\right)$ was significantly larger than those found in the cadaver study $\left(817.2 \mathrm{~mm}^{2}\right)$ [5], in the PNS CT study $\left(752.76 \mathrm{~mm}^{2}\right)[8]$, and in the MRI study $\left(692 \mathrm{~mm}^{2}\right)$ [9]. The authors assume that the reason for the larger area values of the septal cartilage in our study is the inclusion of the SP, which is the septal tail, with a mean area of $69.46 \mathrm{~mm}^{2}$. Although this structure is thinner and more irregular than the anterior cartilage part of the septum, it can be used as additional cartilage graft material.

Embryologically, the nasal septum is completely cartilaginous at the beginning of gestation and the PPE is formed by endochondral ossification from the 6 month of gestation $[10,11]$. Two ossification centers in the PPE and the vomer are united below the caudal part of the nasal septal cartilage [11]. According to the cadaver study of Van Loosen et al. [12], the cartilaginous 
Table 5 . The harvestable portion of the septal cartilage by age

\begin{tabular}{|c|c|c|c|}
\hline Age group (yr) & $\mathrm{DL}(\mathrm{mm})^{\mathrm{a})}$ & $\mathrm{CL}(\mathrm{mm})^{\mathrm{b})}$ & $\operatorname{HSC}\left(\mathrm{mm}^{2}\right)^{\mathrm{c})}$ \\
\hline \multicolumn{4}{|l|}{$0-9$} \\
\hline Mean \pm SD & $19.95 \pm 4.37$ & $11.76 \pm 2.69$ & $435.72 \pm 88.70$ \\
\hline Min-max (median) & $14.11-23.30$ (21.19) & $8.39-14.58$ (12.03) & $319.00-518.76(452.57)$ \\
\hline \multicolumn{4}{|l|}{$10-19$} \\
\hline Mean \pm SD & $23.83 \pm 3.93$ & $14.89 \pm 2.81$ & $655.36 \pm 167.89$ \\
\hline Min-max (median) & $16.84-32.20(23.18)$ & $10.25-18.53(15.04)$ & $334.40-889.67(656.25)$ \\
\hline \multicolumn{4}{|l|}{$20-29$} \\
\hline Mean \pm SD & $19.95 \pm 5.33$ & $16.03 \pm 2.30$ & $549.84 \pm 151.26$ \\
\hline Min-max (median) & $10.43-28.56(20.49)$ & $12.47-21.03(15.80)$ & $307.18-872.74(515.24)$ \\
\hline \multicolumn{4}{|l|}{$30-39$} \\
\hline Mean \pm SD & $20.13 \pm 5.10$ & $15.56 \pm 2.17$ & $513.35 \pm 164.56$ \\
\hline Min-max (median) & $10.35-31.61$ (19.56) & $11.63-20.58$ (15.20) & $225.95-798.88$ (462.08) \\
\hline \multicolumn{4}{|l|}{$40-49$} \\
\hline Mean \pm SD & $19.07 \pm 4.74$ & $16.45 \pm 3.96$ & $496.97 \pm 162.90$ \\
\hline Min-max (median) & $10.14-27.65$ (18.63) & $9.26-27.20(17.04)$ & $222.90-908.73(510.79)$ \\
\hline \multicolumn{4}{|l|}{$50-59$} \\
\hline Mean \pm SD & $17.01 \pm 2.79$ & $14.56 \pm 2.80$ & $442.26 \pm 191.51$ \\
\hline Min-max (median) & $13.60-21.09$ (16.99) & 11.30-20.17 (14.11) & $187.87-687.80(443.73)$ \\
\hline \multicolumn{4}{|l|}{$60-69$} \\
\hline Mean \pm SD & $17.86 \pm 4.75$ & $14.52 \pm 2.51$ & $371.48 \pm 126.99$ \\
\hline Min-max (median) & 10.26-23.14 (19.49) & $10.58-18.96(14.76)$ & $175.04-598.91$ (346.79) \\
\hline \multicolumn{4}{|l|}{$70-99$} \\
\hline Mean \pm SD & $16.55 \pm 4.80$ & $13.46 \pm 3.08$ & $358.08 \pm 162.57$ \\
\hline Min-max (median) & $10.39-23.47(16.05)$ & $8.89-19.31(12.66)$ & $168.69-747.25$ (301.45) \\
\hline Total & $19.58 \pm 5.09$ & $15.15 \pm 3.13$ & $497.32 \pm 181.65$ \\
\hline
\end{tabular}

\section{Table 6 . The harvestable portion of the septal cartilage by gender}

\begin{tabular}{|lccc|}
\hline Gender & DL $(\mathbf{m m})$ & CL $(\mathbf{m m})$ & HSC (mm $\left.{ }^{2}\right)$ \\
\hline Male & & & $540.89 \pm 168.31$ \\
Mean \pm SD & $20.71 \pm 4.74$ & $15.77 \pm 2.69$ & $224.05-908.73(519.37)$ \\
Min-max (median) & $10.14-32.20(20.91)$ & $8.39-24.02(15.75)$ & $378.46 \pm 165.44$ \\
Female & $16.48 \pm 4.62$ & $13.46 \pm 3.63$ & $168.69-731.34(364.71)$ \\
Mean \pm SD & $10.26-26.36(15.48)$ & $8.89-27.20(12.66)$ & $<0.001$ \\
Min-max (median) & $<0.001$ & $<0.001$ & \\
P-value & & \\
\hline The linear dimensions and area of the harvestable septal cartilage assuming preservation of a 10-mm-wide L-strut according to gender. \\
DL, dorsal length of the harvestable septal cartilage; CL, caudal length of the harvestable septal cartilage; HSC, harvestable septal cartilage; SD, standard deviation. \\
a)Chi-squared test.
\end{tabular}

septum develops rapidly in size during the first years of life, with the total area remaining constant after the age of 2 years. In contrast, endochondral ossification of the cartilaginous septum resulting in the formation of the PPE begins after the first 6 months of life and continues until age 36 years $[10,11]$.

In the analysis by age group, the total nasal septum grew rapidly from the child to teenage group. Thereafter, the total septum showed no significant change from $2,580.52 \mathrm{~mm}^{2}$ in the twenties group to $2,325.17 \mathrm{~mm}^{2}$ in the over 70 age group $(\mathrm{P}>0.05)$.

Whereas the area of the total nasal septum remained constant after the teen years, the septal cartilage showed different developmental progression, with a gradual decrease with age (Fig. 6). Our data showed a rapid increase in the area of the septal cartilage until puberty and thereafter decreased significantly from 1,055.03 $\mathrm{mm}^{2}$ in the teenage group to $696.92 \mathrm{~mm}^{2}$ in the over 70 group $(\mathrm{P}<0.05)$. This change was caused by the ossification process of the septal cartilage to the PPE. These findings were similar to those found in other studies [8-11]. By the analysis of measurement according to age group, we can explain the development of the septal cartilage. The total area of the septal cartilage decreases 
Fig. 6. The decrease in the septal cartilage area with age

The decreasing area of the septal cartilage with age from a midsagittal perspective. The septal cartilage (blue area) in the 20s (A), in the $40 \mathrm{~s}(\mathrm{~B})$, and in the $60 \mathrm{~s}(\mathrm{C})$. Values $\left(\mathrm{mm}^{2}\right)$ are presented as the mean area of the septal cartilage in each age group.
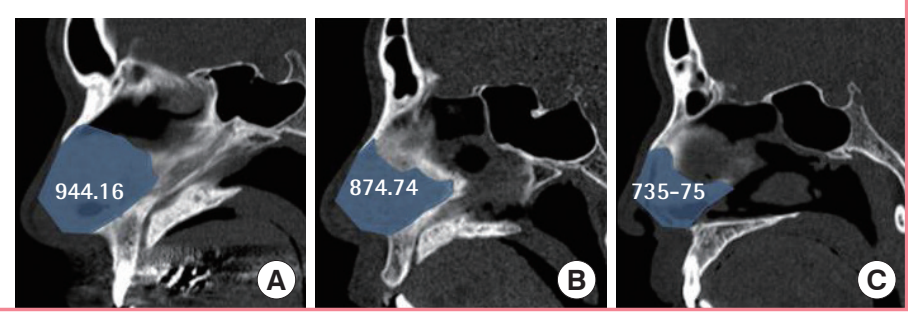

due to the reduction of new cartilaginous formation and the increase of cartilaginous loss by the ossification process after the teen years due to aging.

Therefore, rhinoplasty using a septal procedure should only be performed after puberty due to a high risk of nasal growth impairment at that age [13]. In addition, in the elderly, the keystone area of the nasal bone, which is a clinically important structure for maintaining the stability of the dorsum of the nose, becomes weak due to the decrease in the volume of septal cartilage by ossification. According to the cadaver and MRI studies of Kim et al. [9,14], a small septal cartilage area was significantly correlated with a short overlap length between the nasal bone and septal cartilage below the nasal bone, and the overlap length of the septal cartilage was $7 \pm 2 \mathrm{~mm}$ in adults, which decreased with age, possibly due to the calcification of the septal cartilage. Therefore, if the nasal bone in the rhinion area is removed during hump resection $>7 \mathrm{~mm}$ from the caudal margin, the overlap was mostly damaged. In addition, the overlap area between the PPE and the septal cartilage can be damaged in elderly patients in a similar way because the process of the cartilage calcification is the same both in this area and in the rhinion area. In other words, the relatively high proportion of the calcified cartilage in the area of overlap between the PPE and the septal cartilage as well as in the rhinion may result in greater susceptibility to damage from external trauma for older people than for young people with a low proportion of calcified cartilage. In addition, the nasal bone and cartilage of elderly patients provide less strength and support [15]. In general, the process of cartilage calcification and ossification is the same in the physeal (primary growth center) and epiphyseal (secondary growth center) growth plates. Therefore, due to the risk of damaging the overlapping nasal septal cartilage area of elderly patients that is smaller due to ossification, great care should be taken in the keystone area during the septal procedure to prevent a saddle nose deformity.

In a gender comparison, most studies $[8,9]$ have reported that the total nasal septum area was significantly larger in the males than females, but the septal cartilage was not significantly different in size. However, in this study, the areas of both the total nasal septum and the septal cartilage were significantly greater in the males than females $(\mathrm{P}<0.05)$.

In the septal cartilage graft harvesting procedure, a $10-\mathrm{mm}$ wide safety L-strut should be left under the nasal bone. We found the harvestable cartilage graft size excluding the L-strut to be and $15.15 \pm 3.13 \mathrm{~mm}$, respectively. Those mean lengths were $18.0 \mathrm{~mm}$ and $12.1 \mathrm{~mm}$ in the cadaver study [6] and $18.2 \mathrm{~mm}$ and $15.1 \mathrm{~mm}$ in the cosmetic study [7]. In the procedure for rhinoplasty using a septal cartilage graft, we usually shape the septal cartilage into a large rectangle with one or two pieces. Because the amount of septal cartilage can be insufficient, it is very helpful to predict the amount and shape of the harvestable cartilage graft before surgery.

Among the limitations of this study, it should be noted that even though patients with severe septal deviations were excluded from this study, some measurement errors could have occurred in those with mild septal deviation.

In conclusion, we can gather valuable information about the nasal septum from a 3D facial bone CT scan before rhinoplasty. Because the nasal septum develops rapidly until adolescence, rhinoplasty with septal cartilage harvesting should be performed after the teen years for the prevention of nasal growth impairment. Septal harvesting surgery should be performed with great care in elderly patients because of the high risk of saddle nose deformity by the weakening of the keystone area.

\section{REFERENCES}

1. Rohrich RJ, Ahmad J. Open technique rhinoplasty. In: Warren RJ, Neligan PC, editors. Plastic surgery. 3rd ed. New York: Saunders Elsevier; 2012. p.387-412.

2. Sajjadian A, Rubinstein R, Naghshineh N. Current status of grafts and implants in rhinoplasty: part I. Autologous grafts. Plast Reconstr Surg 2010;125:40e-9e.

3. Rohrich RJ, Hollier LHJ, Landecker A. Harvesting cartilage grafts for primary rhinoplasty. In: Gunter JP, Rohrich RJ, Adams WPJ, editors. Dallas rhinoplasty: nasal surgery by the masters. 2nd ed. St. Louis, MO: Quality Medical Pub.; 2007. p.177-86.

4. Daniel RK. Rhinoplasty: an atlas of surgical techniques. 
New York: Springer-Verlag; 2001.

5. Miles BA, Petrisor D, Kao H, et al. Anatomical variation of the nasal septum: analysis of 57 cadaver specimens. Otolaryngol Head Neck Surg 2007;136:362-8.

6. Kim JS, Jang PY, Choi TH, et al. The dimension of the septal cartilage using the cadaver study. J Korean Soc Aesthetic Plast Surg 2006;12:29-32.

7. Kim JS, Khan NA, Song HM, et al. Intraoperative measurements of harvestable septal cartilage in rhinoplasty. Ann Plast Surg 2010;65:519-23.

8. Kim J, Cho JH, Kim SW, et al. Anatomical variation of the nasal septum: Correlation among septal components. Clin Anat 2010;23:945-9.

9. Kim IS, Lee MY, Lee KI, et al. Analysis of the development of the nasal septum according to age and gender using MRI. Clin Exp Otorhinolaryngol 2008;1:29-34.

10. Huizing $\mathrm{BH}$, de Groot J. Functional reconstructive nasal surgery. In: Kheirandish-Gozal L, Gozal D, editors. Sleep dis- ordered breathing in children: a comprehensive clinical guide to evaluation and treatment. New York: Humana press; 2012. p.37-8.

11. Huizing BH, de Groot J. Functional reconstructive nasal surgery. New York: Thime; 2003.

12. Van Loosen J, Van Zanten GA, Howard CV, et al. Growth characteristics of the human nasal septum. Rhinology 1996; 34:78-82.

13. Rees TD. Surgical correction of the severely deviated nose by extramucosal excision of the osseocartilaginous septum and replacement as a free graft. Plast Reconstr Surg 1986;78: 320-30.

14. Kim IS, Chung YJ, Lee YI. An anatomic study on the overlap patterns of structural components in the keystone area in noses of Koreans. Clin Exp Otorhinolaryngol 2008;1:158-60.

15. Rohrich RJ, Hollier LH Jr, Janis JE, et al. Rhinoplasty with advancing age. Plast Reconstr Surg 2004;114:1936-44. 